\title{
DETERMINAN STATUS GIZI BALITA DI DESA ALUE NAGA BANDA ACEH
}

\author{
Determinant Of Nutrition Status In Children Alue Naga Banda Aceh \\ ${ }^{1}$ Mira abdullah, ${ }^{2}$ Erni Salfitri \\ ${ }^{1,2}$ Fakultas Ilmu Kesehatan, Universitas Ubudiyah Indonesia, Banda Aceh
}

Email: $\underline{\text { mira@uui.ac.id }}$

\begin{abstract}
ABSTRAK
Perkembangan masalah gizi di Indonesia semakin kompleks saat ini, selain masih menghadapi masalah kekurangan gizi, masalah kelebihan gizi juga menjadi persoalan yang harus di tangani dengan serius. Dalam Rencana Pembangunan Jangka Menengah Nasional 2010-2014, perbaikan status gizi masyarakat merupakan salah satu prioritas dengan menurunkan prevalensi balita gizi kurang (underweight) menjadi $15 \%$ dan prevalensi balita pendek (stunting) menjadi 32\% pada tahun 2014. Untuk mengetahui determinan status gizi balita di Desa Alue Naga Banda Aceh.Penelitian ini bersifat deskriptif analitik dengan pendekatan crossectional. Pengumpulan data dilakukan pada tanggal 2 Juni tahun 2016. Sampel dalam penelitian ini adalah balita yang berjumlah 68 orang. Pengumpulan data dilakukan dengan membagikan kuesioner. Kemudian di uji statistik mengunakan chi-quare. Hasil penelitian analisa data univariat menunjukkan bahwa responden yang mengalami status gizi kurang yaitu 68,6\% berjenis kelamin laki-laki. Dan responden dengan status gizi kurang yaitu $71,8 \%$ pada ibu yang multipara. Sedangkan responden dengan status gizi kurang yaitu $72,5 \%$ tidak diberikan imunisasi. Sedangkan hasil analisa data bivariat menunjukkan bahwa hubungan jenis kelamin dengan status gizi balita didapatkan hasil pvalue 0,030. Hubungan paritas dengan status gizi balita didapatkan p-value $=0,002$. Sedangkan hubungan imunisasi dengan status gizi balita didapatkan $\mathrm{p}$-value $=0,001$. Ada hubungan status gizi balita dengan jenis kelamin, paritas, dan imunisasi. Untuk itu diharapkan kepada ibu balita agar lebih memperhatikan status gizi balita seperti mengatur jumlah anak dan memberikan imunisasi yang lengkap.
\end{abstract}

\section{Kata Kunci : Status gizi balita, Jenis kelamin, Paritas dan Imunisasi}

\begin{abstract}
The development of nutritional problems in Indonesia is increasingly complex now, aside from still facing the problem of malnutrition, the problem of over nutrition is also a problem that must be dealt with seriously. In the National Medium-Term Development Plan 2010-2014, improving the nutritional status of the community is one of the priorities by reducing the prevalence of underweight children to $15 \%$ and the prevalence of short toddlers (stunting) to $32 \%$ in 2014. To determine the determinants of the nutritional status of toddlers in Alue Naga Village Banda Aceh. This research is analytic descriptive with cross-sectional approach. Data collection was conducted on June 2, 2016. Samples in this study were toddlers, amounting to 68 people. Data collection is done by distributing questionnaires. Then the statistical test uses chi-quare. The results of the analysis of univariate data analysis showed that respondents who experienced poor nutritional status were $68.6 \%$ male. And respondents with poor nutritional status is $71.8 \%$ in multiparous mothers. While respondents with poor nutritional status that is $72.5 \%$ were not given immunizations. While the results of the bivariate data analysis showed that the relationship between sex and nutritional status of children obtained a p-value of 0.030. The relationship of parity with the nutritional status of children under five obtained p-value = 0.002. While the relationship of immunization with the nutritional status of children under five
\end{abstract}


Journal of Healthcare Technology and Medicine Vol. 4 No. 2 Oktober 2018 Universitas Ubudiyah Indonesia

e-ISSN : 2615-109X

is obtained $p$-value $=0.001$. There is a relationship between the nutritional status of children under five with gender, parity, and immunization. For this reason it is expected that mothers of toddlers pay more attention to the nutritional status of children under five, such as regulating the number of children and providing complete immunizations.

Keywords: Nutrition status of toddlers, Gender, Parity and Immunization

\section{PENDAHULUAN}

Status gizi adalah keadaan kesehatan individu atau kelompok yang ditentukan oleh derajat kebutuhan fisik akan energi dan zat-zat yang diperoleh dari beragam makanan yang berdampak fisiknya di ukur secara antropometri. Kurus gemuknya seorang anak sebabnya dipengaruhi oleh status gizinya. Berdasarkan nilai baku standar arvard status gizi dapat dibagi menjadi tiga yaitu : gizi lebih, gizi kurang dan gizi buruk (Supariasa, 2002).

Menurut World Health Organiztion (WHO) pada tahun 2004 terdapat sekitar 54\% balita didasari oleh keadaan gizi yang jelek. Sedangkan menurut Departemen Kesehatan (2007) pada tahun 2006 terdapat sekitar 27,5\% (5 juta balita gizi buruk dan gizi kurang), 3,5 juta anak balita atau sekitar $(19,19 \%)$ dalam tingkat gizi kurang, dan 1,5 juta anak balita gizi buruk (8,3\%). Pada tahun 2008 berdasarkan data SUSENAS prevalensi status gizi anak balita untuk gizi kurang sebesar 19,20\% dan gizi buruk 8,8 \%. Tidak ada penurunan yang berantai antara tahun 2006 dan 2008. Prevalensi balita gizi buruk merupakan indikator Millenium Development Goals (MDGs) yang harus dicapai disuatu daerah (kabupaten/kota) pada tahun 2015, yaitu terjadinya penurunan prevalensi balita gizi buruk menjadi 3,6\% atau kekurangan gizi pada anak balita menjadi 15,5 \% (BAPPENAS, 2010).

Propinsi Aceh sebagai salah satu Provinsi Indonesia sampai saat ini juga masih menghadapi permasalahan terkait status gizi Balita. Berdasarkan profil kesehatan Propinsi Aceh tahun 2013 diketahui bahwa dari 23 kabupaten di Aceh terdapat 16.099 balita dengan prevalensi 12,7 \% yang mengalami gizi kurang. Pada tahun 2010 sampai dengan 2013 terdapat 759 balita dengan prevalensi 0,6 \% mengalami gizi buruk (Profil Kesehatan Aceh, 2013).

Prevalensi status gizi kurang pada balita kota Sabang yaitu 10,9\% ( Riskesdas, Provinsi Aceh 2013). Studi pendahuluan yang dilakukan di Puskesmas Sukakarya Kota Sabang tercatat pada tahun 2015 terdapat 1.097 balita yang ada di wilayah kerja Puskesmas Sukakarya Kota Sabang yang terdiri dari 6 desa. 5 dari 6 desa memiliki balita yang mengalami gizi kurang, urutan desa tersebut dari status gizi kurang tertinggi sampai terendah adalah (1) Kota Bawah Barat (7\%), (2) Kota Bawah Timur (5\%), (3) Paya Seunara (3\%), (4) Kota Atas (2\%), (5) Krueng Raya (2\%). Data jumlah balita di desa Kota Bawah Barat 
Journal of Healthcare Technology and Medicine Vol. 4 No. 2 Oktober 2018

Universitas Ubudiyah Indonesia

e-ISSN : 2615-109X

pada tahun 2016 sebanyak 214 orang. Desa Kota Bawah Barat Sabang merupakan salah satu desa wilayah kerja Puskesmas Sukakarya Kota Sabang yang memiliki jumlah balita gizi kurang terbanyak di antara desa lainnya yaitu berkisar $7 \%$ yang hampir mendekati angka prevalensi gizi kurang kota Sabang yaitu 10,9\%. Berdasarkan permasalahan di atas, maka peneliti ingin melakukan penelitian tentang "Determinan status gizi balita di Desa Alue Naga Banda Aceh”.

\section{METODE PENELITIAN}

Jenis penelitian ini bersifat deskriptif analitik yaitu dengan menggunakan rancangan cross sectional. Dalam penelitian ini akan di gambarkan tentang "Determinan status gizi balita di Desa Alue Naga Banda Aceh. Populasi adalah keseluruhan subyek penelitian (Arikunto, 2006). Populasi dalam penelitian ini adalah seluruh balita di Desa Alue Naga Kota Banda Aceh yaitu sebanyak 214 orang.

Instrumen dalam penelitian ini adalah sebagai berikut :

a. Untuk mengetahui status gizi anak balita di ukur dengan memperhatikan BB/U yang digolongkan berdasarkan Z-Score yaitu :

$$
\begin{array}{ll}
\text { Gizi baik } & :-2 \text { SD sampai } 2 \text { SD } \\
\text { Gizi kurang } & :-3 \text { SD sampai <- 2 SD }
\end{array}
$$

b. Paritas dengan kriteria penilaian jika primipara ibu yang melahirkan anak hidup yaitu satu kali, dan multipara ibu yang melahirkan anak hidup dibawah lima kali.

c. Status imunisasi melihat buku KMS responden dengan kriteria penilaian jika lengkap diberikan nilai 1 dan jika tidak lengkap diberikan nilai 0.

\section{HASIL DAN PEMBAHASAN}

Hubungan jenis kelamin dengan status gizi balita

Tabel 1

\section{Hubungan Jenis Kelamin dengan Status Gizi Balita di Desa Alue Naga Banda Aceh Tahun 2016}

Status Gizi

\begin{tabular}{llll}
\cline { 2 - 3 } Jenis Kelamin & Gizi baik & Gizi kurang & Total \\
\end{tabular}


Journal of Healthcare Technology and Medicine Vol. 4 No. 2 Oktober 2018

Universitas Ubudiyah Indonesia

e-ISSN : 2615-109X

Value

\begin{tabular}{lccccccc} 
& $\mathrm{f}$ & $\%$ & $\mathrm{f}$ & $\%$ & $\mathrm{Jlh}$ & $\%$ & \\
\hline Laki-laki & 11 & 31,4 & 24 & 68,6 & 35 & 100 & 0,030 \\
& & & & & & & \\
Perempuan & 20 & 60,6 & 13 & 39,4 & 33 & 100 & \\
\hline
\end{tabular}

Berdasarkan tabel 1 dapat dilihat bahwa responden dengan status gizi kurang yaitu $68,6 \%$ berjenis kelamin laki-laki lebih banyak dibandingkan dengan responden jenis kelamin perempuan yaitu $39,4 \%$. Berdasarkan uji stastistik dalam penelitian ini terhadap hubungan jenis kelamin dengan status gizi balita didapatkan p- value $0,030,<\alpha=0,05$ artinya ada hubungan antara jenis kelamin dengan status gizi balita di Desa Alue Naga Banda Aceh.

Hubungan paritas ibu dengan status gizi balita

Tabel 2

Hubungan Paritas dengan Status Gizi Balita di Desa Alue Naga Banda Aceh Tahun 2016

\begin{tabular}{|c|c|c|c|c|c|c|c|}
\hline \multirow{3}{*}{ Paritas } & \multicolumn{6}{|c|}{ Status Gizi } & \multirow{3}{*}{$\begin{array}{c}\text { p- } \\
\text { Value }\end{array}$} \\
\hline & \multicolumn{2}{|c|}{ Gizi baik } & \multicolumn{2}{|c|}{ Gizi kurang } & \multicolumn{2}{|c|}{ Total } & \\
\hline & $\mathrm{f}$ & $\%$ & $\mathrm{f}$ & $\%$ & $\mathrm{Jlh}$ & $\%$ & \\
\hline Primipara & 20 & 69 & 9 & 31 & 29 & 100 & 0,002 \\
\hline Multipara & 11 & 28,2 & 28 & 71,8 & 39 & 100 & \\
\hline
\end{tabular}

Berdasarkan tabel 2 dapat dilihat bahwa responden dengan status gizi kurang yaitu $71,8 \%$ pada ibu yang multipara lebih banyak dibandingkan dengan ibu yang primipara yaitu sebanyak $31 \%$. Berdasarkan uji stastistik dalam penelitian ini terhadap hubungan paritas dengan status gizi balita didapatkan $\mathrm{p}$ - value $=0,002,<\alpha=0,05$ artinya ada hubungan antara paritas dengan status gizi balita di Desa Alue Naga Banda Aceh.

Hubungan imunisasi dengan status gizi balita

Tabel 3

Hubungan Imunisasi dengan Status Gizi Balita di Desa Alue Naga Banda Aceh Tahun 2016

Status Gizi 


\begin{tabular}{lccccccc}
\cline { 2 - 6 } \multicolumn{1}{c}{ Imunisasi } & Gizi baik & Gizi kurang & Total & \multirow{2}{p}{$\begin{array}{c}\text { p- } \\
\text { Value }\end{array}$} \\
\cline { 2 - 6 } & $\mathrm{f}$ & $\%$ & $\mathrm{f}$ & $\%$ & $\mathrm{Jlh}$ & $\%$ & \\
\hline Lengkap & 20 & 71,4 & 8 & 28,6 & 28 & 100 & 0,001 \\
Tidak lengkap & 11 & 27,5 & 29 & 72,5 & 40 & 100 & \\
\hline
\end{tabular}

Berdasarkan tabel 3 dapat dilihat bahwa responden dengan status gizi kurang yaitu 72,5\% diberikan imunisasi tidak lengkap lebih banyak dibandingkan dengan responden diberikan imunisasi lengkap diberikan imunisasi yaitu 28,6\%. Berdasarkan uji stastistik dalam penelitian ini terhadap hubungan imunisasi dengan status gizi balita didapatkan pvalue $=0,001,<\alpha=0,05$ artinya ada hubungan antara imunisasi dengan status gizi balita di Desa Alue Naga Banda Aceh.

Berdasarkan penelitian yang dilakukan oleh Simanjuntak (2013) yang berjudul Faktor - faktor yang berhubungan dengan status gizi anak balita di kecamatan Siantar Martoba dan Siantar Marihat Kota Pematangsiantar. Hasil penelitian menunjukkan ada hubungan jenis kelamin dengan status gizi balita dengan $\mathrm{p}$ - value 0,000 . Sedangkan menurut penelitian Yulia (2009) yang berjudul: Analisa faktor-faktor yang berhubungan dengan status gizi balita di Posyandu di Kota Tangerang”. Hasil penelitian didapatkan p-value 0,006 artinya ada hubungan jenis kelamin dengan status gizi balita. Hal ini disebabkan karena banyak balita laki-laki yang mengalami gizi kurang dibandingkan dengan balita perempuan.

Menurut Hungu (2007) jenis kelamin (seks) adalah perbedaan antara perempuan dengan laki-laki secara biologis sejak seseorang lahir. Kebutuhan zat gizi anak laki-laki berbeda dengan anak perempuan dan biasanya lebih tinggi karena anak laki-laki memiliki aktivitas fisik yang lebih tinggi. Anak laki-laki biasanya mendapatkan prioritas yang lebih tinggi dalam hal makanan dibandingkan anak perempuan (Soetjiningsih, 2014).

Peneliti berasumsi bahwa dalam penelitian ini ada hubungan jenis kelamin dengan status gizi balita. Hal ini disebabkan karena jenis kelamin laki-laki lebih banyak mengalami status gizi kurang. Jenis kelamin merupakan faktor penentu terjadinya pertumbuhan balita.

Peneliti berasumsi bahwa dalam penelitian ini ditemukan adanya hubungan paritas dengan status gizi balita. Hasil penelitian ditemukan banyak ibu yang multipara mengalami status gizi balita yang kurang dibandingkan dengan ibu yang primipara. Hal ini disebabkan 
Journal of Healthcare Technology and Medicine Vol. 4 No. 2 Oktober 2018

Universitas Ubudiyah Indonesia

e-ISSN : 2615-109X

karena ibu yang melahirkan lebih dari satu anak kurang memperhatikan status gizi balita dan telah berkurangnya pola asuh yang diberikan dalam kehidupan sehari-hari.

Peneliti berasumsi bahwa dari hasil penelitian ini ditemukan adanya hubungan imunisasi dengan status gizi balita. Hal ini disebabkan karena banyak balita yang tidak diberikan imunisasi yang lengkap mengalami gizi yang kurang. Jika balita telah diimunisasi secara lengkap maka balita telah diberikan pencegahan untuk menghadapi berbagai macam penyakit. Penyakit yang timbul pada balita akan menyebabkan penurunan berat badan yang dapat menyebabkan status gizi kurang.

Imunisasi merupakan vaksin yang dimasukkan kedalam tubuh yang berguna untuk daya tahan tubuh balita. Jika balita tidak mendapatkan imunisasi maka daya tahun tubuh balita akan menjadi lemah dan mudah terkena penyakit dilingkungan sekitarnya. Untuk mencegah terjadinya penyakit maka diharapkan balita diberikan imunisasi yang lengkap sehingga akan memperbaiki pertumbuhan dan Perkembangan balita.

\section{KESIMPULAN}

1. Ada hubungan jenis kelamin dan status gizi balita dengan $p$-value 0,030 di Desa Alue Naga Banda Aceh.

2. Ada hubungan paritas dan status gizi balita dengan p-value 0,002 di Desa Alue Naga Banda Aceh.

3. Ada hubungan imunisasi dan status gizi balita dengan p-value 0,001 di Desa Alue Naga Banda Aceh .

\section{DAFTAR PUSTAKA}

Achadi. 2007. Gizi Dan Kesehatan Masyarakat. Jakara: Raja Grafindo

Almatsier. 2010. Prinsip Dasar Ilmu Gizi, cetakan kesembilan. Jakarta: Pustaka Utama Arikunto, S. 2006. Prosedur Penelitian suatu Pendekatan Praktik. Jakarta: Rineka Cipta BAPPENAS. 2010. Laporan Pencapaian Tujuan Pembangunan Milenium Indonesia 2010. Jakarta: BAPPENAS atau KPPN

Manuaba, I.B.G. 2010. Ilmu Kebidanan, penyakit Kandungan dan KB untuk Pendidikan Bidan Edisi 2. Jakarta: EGC

Maryunani. 2010. Ilmu Kesehatan Anak Dalam Kebidanan. Jakarta: Trans Info Media 
Journal of Healthcare Technology and Medicine Vol. 4 No. 2 Oktober 2018

Universitas Ubudiyah Indonesia

e-ISSN : 2615-109X

Notoatmodjo, S. 2010. Metode Penelitian Kesehatan. Jakarta: PT Rineka Cipta

Proverawati, A. Wati. 2010. Imunisasi dan Vaksinasi. Jakarta: Nuha Offset Riskesdas. 2013. Badan Penelitian dan Pengembangan Kesehatan RI. Jakarta:

Riskesdas

Balita Di Kecamatan Siantar Martoba Dan Siantar Marihat Kota Pematangsiantar. Depok: Skripsi FKM UI

Soekirman. 2000. Ilmu Gizi dan Aplikasinya. Jakarta: Departemen Pendidikan Nasional

WHO. 2012. Interpretation Guide Nutrition Landscape Information System (NLIS) Country Profil Indicators. Jakarta: Depkes RI

Yulia. 2009. Analisa Faktor-faktor Yang Berhubungan Dengan Status Gizi Balita di Posyandu di Kota Tangerang. Tesis FKM U 
